\title{
Dielectric Permittivity of Various Cement-Based Materials during the First 24 Hours Hydration
}

\author{
Natt Makul \\ Faculty of Industrial Technology, Phranakhon Rajabhat University, Bangkok, Thailand \\ Email: shinomomo7@hotmail.com
}

Received May 12, 2012; revised February 23, 2013; accepted August 26, 2013

Copyright (C) 2013 Natt Makul. This is an open access article distributed under the Creative Commons Attribution License, which permits unrestricted use, distribution, and reproduction in any medium, provided the original work is properly cited.

\begin{abstract}
The dielectric permittivity of cementitious materials during 24 hours hydration period at a frequency of $2.45 \mathrm{GHz}$ using a network analyzer with open-ended probe technique was measured. Influences of water-to-cementitious ratios, cement types, pozzolans and aggregate types are taken into consideration. The results show that dielectric permittivity is strongly affected by initial water-to-cementitious ratio and the rate of hydration reaction which can be changed by fineness of cement (Types 1 and 3), pozzolan materials and aggregates (river sand with/without crushed limestone rock). Dielectric permittivity is relatively high and remains constant during the dormant period, after that it decreases rapidly when the hydration reaction resumes and continues to decrease during the acceleratory period.
\end{abstract}

Keywords: Dielectric Permittivity; Cementitious Materials; Hydration; Microwave Energy

\section{Introduction}

Microwave energy has been widely used as an innovative material processing for various industrial dielectric materials such as paper, wood, etc. Basically, microwave radiation interacts with the materials through dielectric permittivity resulting in rapid heating. Consequently, dipole interaction and heat generation will take place within dielectric materials which are composed of polar molecules [1].

Can microwave energy be applied to cure cementitious materials? The answer based on theoretical feasibility, is yes. Many research groups [1] have investigated, both experimentally and numerically, the accelerated curing of cements in order to gain high strength [2]. However, the actual number of successes has been very limited. A reason for this is lack of understanding of the behavior of dielectric permittivity of cement-based materials which, in fact, are greatly affected by temperature, free moisture content and hydration time. In particular, during the first 24 hours of hydration, it is critical to determine optimum conditions for high performance curing of the cementitious materials using microwave energy [3].

In this paper, the dielectric permittivity of cementbased materials during the initial period of hydration at $2.45 \mathrm{GHz}$ has been investigated by using a network analyzer with an openended probe technique based on the influences of water-to-cementitious ratios, cement types, pozzolan materials and aggregates.

\section{Experiments}

\subsection{Specimen Preparation}

Three groups of 117 specimens having a cubical shape in size of $55 \times 55 \times 110 \mathrm{~mm}^{3}$ were tested for dielectric permittivity, temperature rise and setting time, They were made from Types 1 and 3 Portland cements in accordance with the ASTM C150 [4] pulverized fuel ash in a class of low calcium (Type F) in accordance with the ASTM C 618 [4], and silica fume in accordance with the ASTM C1240 [4]. River sand (FM. = 2.58) and crushed limestone rock (Max. Size $=10 \mathrm{~mm}$ ), having a grade conforming with the ASTM C33 [4], were mixed with tap water to from pastes, mortars and concretes with various proportions, as shown in Table 1. Superplasticizer conforming to the ASTM C494 [4] was used in a recommended dosage $(500 \mathrm{ml}$ per $100 \mathrm{~kg}$ of cementitious materials).

\subsection{Test Procedures}

For measuring dielectric permittivity of cementitious materials in the range of $2.45 \mathrm{GHz}$, a network analyzer with open-ended coaxial probe [5] was used. After mixing and placing into the mold, it was then wrapped by Styrofoam with $5 \mathrm{~mm}$ in thickness in order to protect the 
Table 1. Mixing proportions of pastes, mortars and concretes.

\begin{tabular}{cccccccccc}
\hline Mix symbol & W/C & A/C & \multicolumn{7}{c}{ Material constitutes (air content designed = 1\%) } \\
\cline { 5 - 10 } & & & $\begin{array}{c}\text { Cement } \\
\left(\mathrm{kg} / \mathrm{m}^{3}\right)\end{array}$ & $\begin{array}{c}\text { Pulverized fuel ash } \\
\left(\mathrm{kg} / \mathrm{m}^{3}\right)\end{array}$ & $\begin{array}{c}\text { Silica fume } \\
\left(\mathrm{kg} / \mathrm{m}^{3}\right)\end{array}$ & $\begin{array}{c}\text { Water } \\
\left(\mathrm{kg} / \mathrm{m}^{3}\right)\end{array}$ & $\begin{array}{c}\text { Super plasticizer } \\
\left(\mathrm{L} / \mathrm{m}^{3}\right)\end{array}$ & $\begin{array}{c}\text { Sand } \\
\left(\mathrm{kg} / \mathrm{m}^{3}\right)\end{array}$ & $\begin{array}{c}\text { Lime stone } \\
\left(\mathrm{kg} / \mathrm{m}^{3}\right)\end{array}$ \\
\hline CP1_0.38 & 0.38 & 0 & 1417 & 0 & 0 & 538 & 0 & 0 & 0 \\
CP1_0.45 & 0.45 & 0 & 1290 & 0 & 0 & 579 & 0 & 0 & 0 \\
CP1_0.70 & 0.70 & 0 & 973 & 0 & 0 & 679 & 0 & 0 & 0 \\
CP3_0.38 & 0.45 & 0 & 1419 & 0 & 0 & 539 & 0 & 0 & 0 \\
CP1_0.38SF25 & 0.38 & 0 & 1018 & 0 & 337 & 512 & 0 & 0 & 0 \\
CP1_0.38PFA25 & 0.38 & 0 & 998 & 335 & 0 & 507 & 0 & 0 & 0 \\
M1_0.38 & 0.38 & 2.75 & 561 & 0 & 0 & 212 & 0 & 1546 & 0 \\
M3_0.38 & 0.38 & 2.75 & 561 & 0 & 0 & 212 & 0 & 1546 & 0 \\
M1_0.38SUPS2.75 & 0.38 & 2.75 & 561 & 0 & 0 & 207 & 5.610 & 1544 & 0 \\
M3_0.38SUPS2.75 & 0.38 & 2.75 & 561 & 0 & 0 & 207 & 5.610 & 1543 & 0 \\
C1_0.38SUP & 0.38 & 4.33 & 425 & 0 & 0 & 160 & 3.400 & 805 & 1030 \\
C1_0.45SUP & 0.45 & 4.14 & 425 & 0 & 0 & 189 & 3.400 & 771 & 985 \\
C1_0.70SUP & 0.70 & 3.48 & 425 & 0 & 0 & 296 & 3.400 & 642 & 830 \\
\hline
\end{tabular}

Remarks: CP, M and C represent cement paste, mortar and concrete, respectively. 1 and 3 represent Types of Portland cement. $0.38,0.45$ and 0.70 represent water-to-cementitious materials (cement/Pulverized fuel ash/Silica fume). SF and PFA represent silica fume and pulverized fuel ash, respectively. SUP represents superplasticizer, and 2.75, 4.33, 4.14 and 3.48 represent aggregate-to-cementitious ratio.

heat loss. Both dielectric permittivity and semi-adiabatic temperature using data logger with thermo-couple (Type K) were simultaneously recorded every 180 and 15 minutes, respectively. However, in order to eliminate the effect of thermo-couple embedded in microwave radiation, we tested separately three specimens for dielectric permittivity and three for temperature rise. Furthermore, the setting time of pastes, mortars and concretes were tested by Vicat needle, modified Vicat needle and penetration resistance in accordance with the ASTM C191 [4], ASTM C807 [4], and ASTM C403 [4], respectively.

\section{Results and Discussion}

\subsection{Effect of Water-To-Cementitious Materials}

Figure 1 shows the evolution of dielectric permittivity and simultaneous temperature rise of concretes. It can be observed that the dielectric permittivity at the initial stage is relatively high in comparison with the later stage, and also increases with the increasing water content (higher w/c) in the concrete. This is due to the fact that immediately after the contact between water and cement they start to react and then dissolve $\mathrm{Ca}^{2+}, \mathrm{OH}^{-}$and $\mathrm{SO}_{4}^{2-}$ ions into the system. In addition, during the dormant period, the dielectric permittivity changes very little because the chemical compositions of the aqueous remains remain nearly constant [6].

\subsection{Effect of Cement Types}

Figure 2 shows the changes of permittivity throughout the early stage of 24 hours hydration reaction period.
Permittivity remains at a high level and decreases at the end of the dormant period, approaching to a constant value when the internal structure has been stabilized. The dielectric permittivity of Type 3 pastes is higher than the Type 1 pastes because Portland cement Type 3 has finer grains of tri-calcium aluminate $\left(\mathrm{C}_{3} \mathrm{~A}\right)$ [7] than in the Type 1 causing it to dissolve with a high rate and maintaining an ion-rich system. In addition, the rate of the decrease of dielectric permittivity of Type 3 paste is higher than that of Type 1 . In the acceleratory period, the Type 3 paste reacts faster than the Type I paste. This coincides with temperature rise and shorter dormant period. For setting time, the dielectric constant is maintained until the final setting time because of the high dissolution rate, however the dielectric constant drops dramatically with the high hydration rate. At the later stage after formation of the C-S-H structure, the dielectric permittivity tends to remain constant because of strong constraints imposed by its structure.

\subsection{Effect of Pozzolan Materials}

Effects of silica fume (SF) and pulverized fuel ash (PFA) on dielectric permittivity, temperature rises and setting time of the pastes are shown in Figure 3. The dielectric constant of the paste containing PFA through the first 24 hours hydration time is higher than that of the plain paste, whereas the paste containing SF is lower. Both reactions involving SF and PFA occur as secondary reactions [8]. This means, however, that the PFA can produce excessive water in the paste while increasing $\mathrm{Si}^{3+}$ and $\mathrm{Ca}^{2+}$ ions in the system. This results in an increasing dielectric 


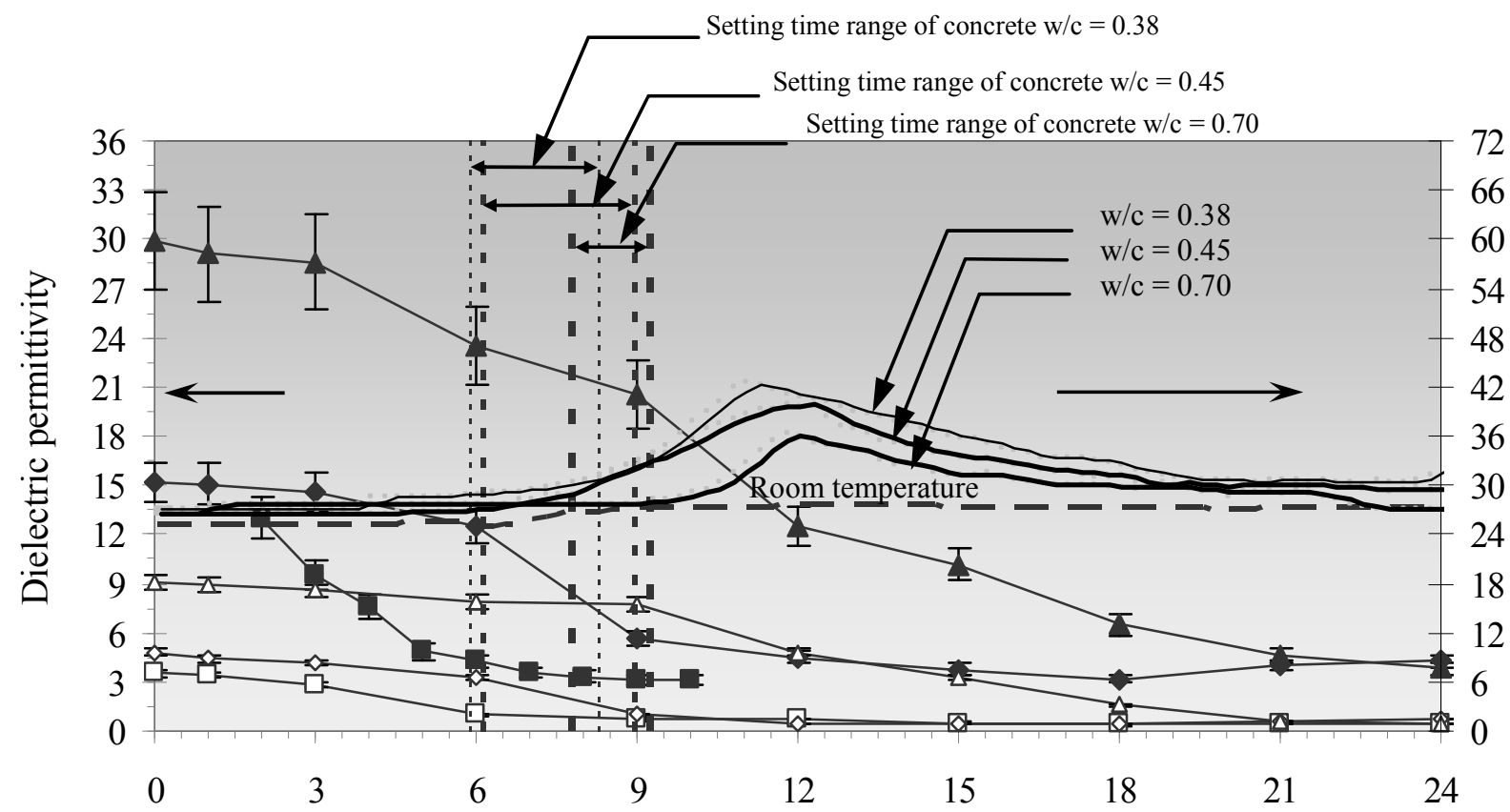

Hydration time (h)

$\square$ Loss factor at $\mathrm{w} / \mathrm{c}=0.38$

$\diamond$ Loss factor at $\mathrm{w} / \mathrm{c}=0.45$

$\triangle$ Loss factor at $\mathrm{w} / \mathrm{c}=0.70$
Dielectric constant at $\mathrm{w} / \mathrm{c}=0.38$

Dielectric constant at $\mathrm{w} / \mathrm{c}=0.45$

Dielectric constant at $\mathrm{w} / \mathrm{c}=0.70$

Figure 1. Dielectric permittivity of concretes with different w/c ratios.

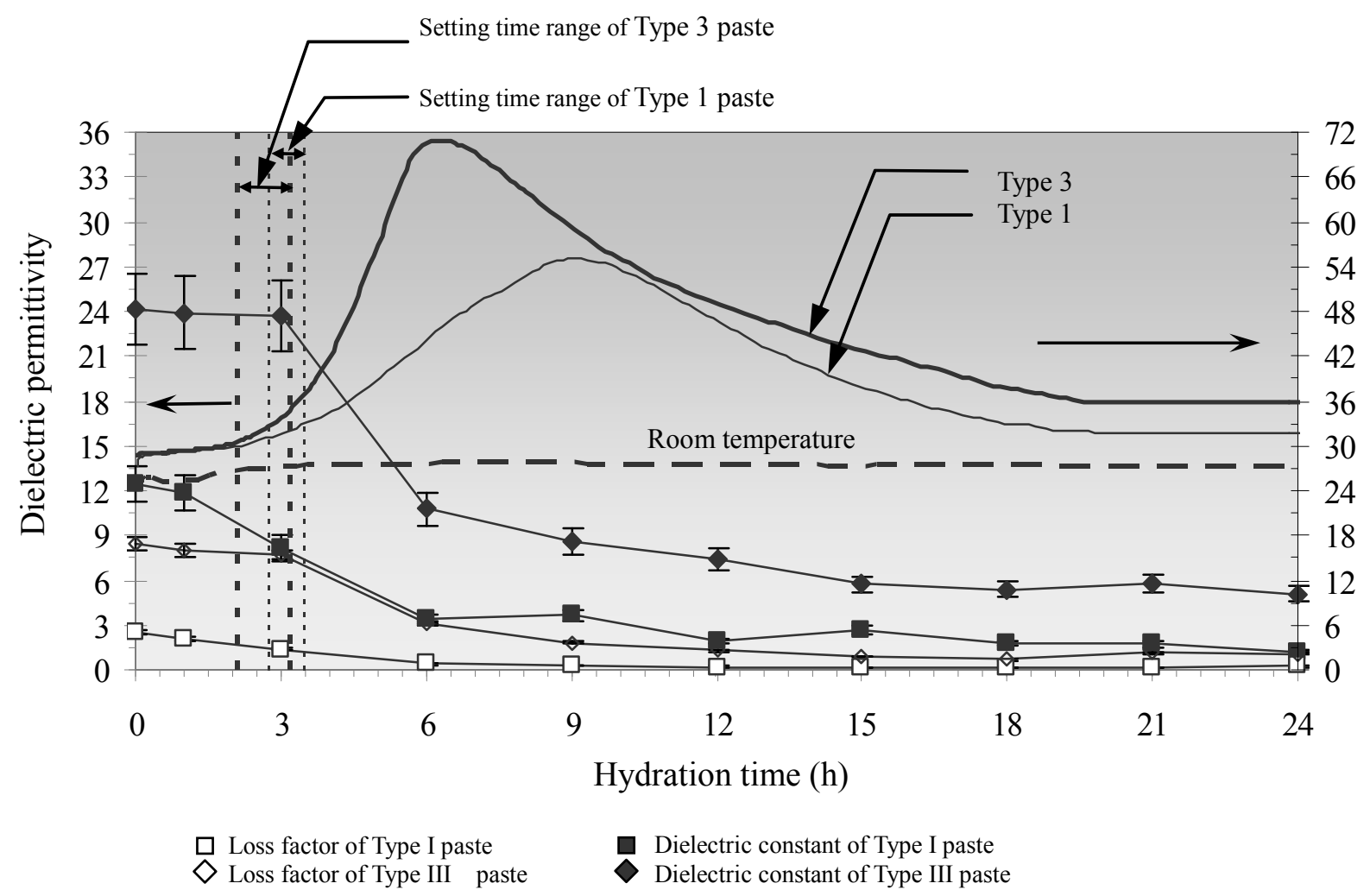

Figure 2. Dielectric permittivity of pastes with different cement types. 

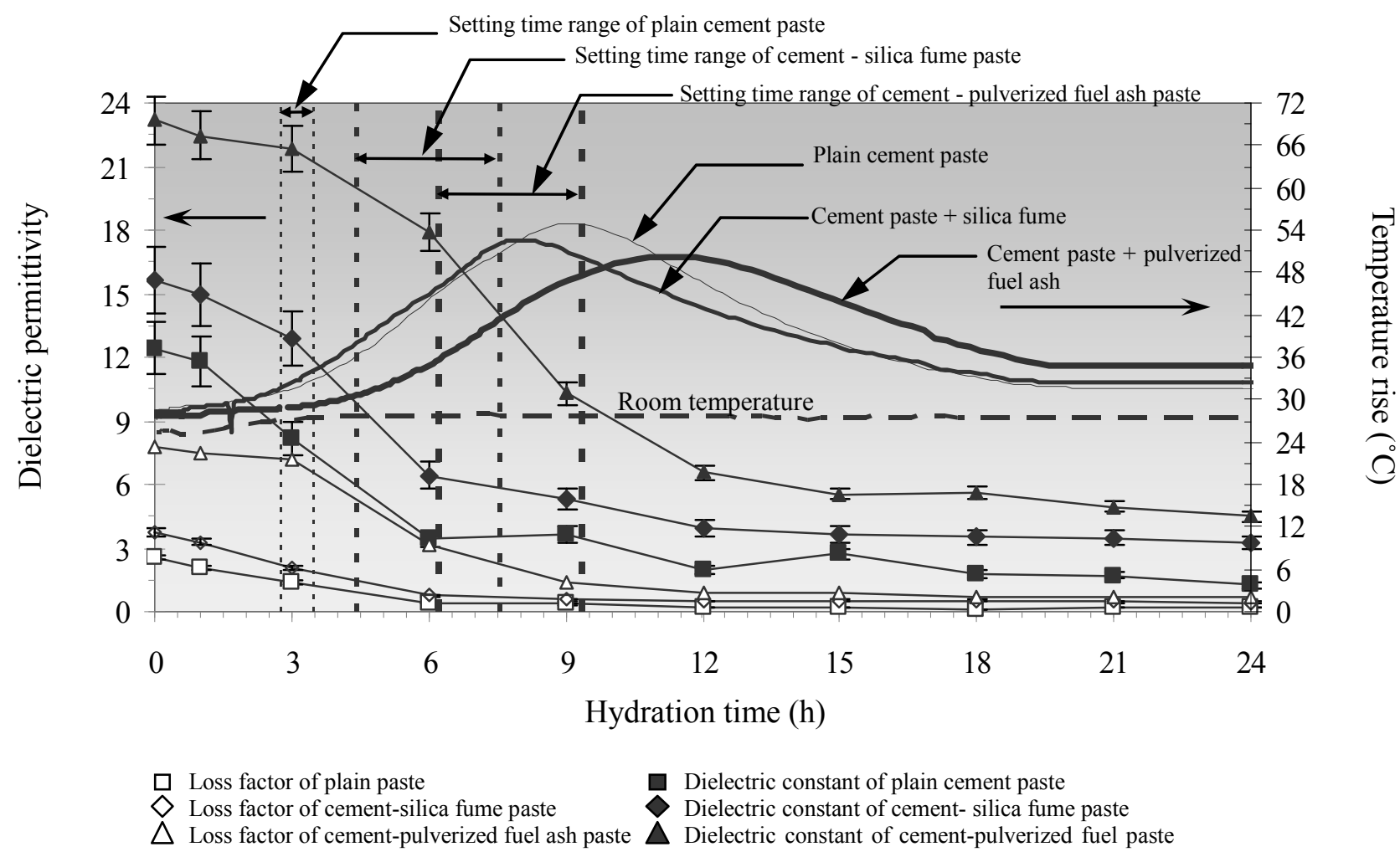

Figure 3. Dielectric permittivity of pastes with different pozzolan materials.

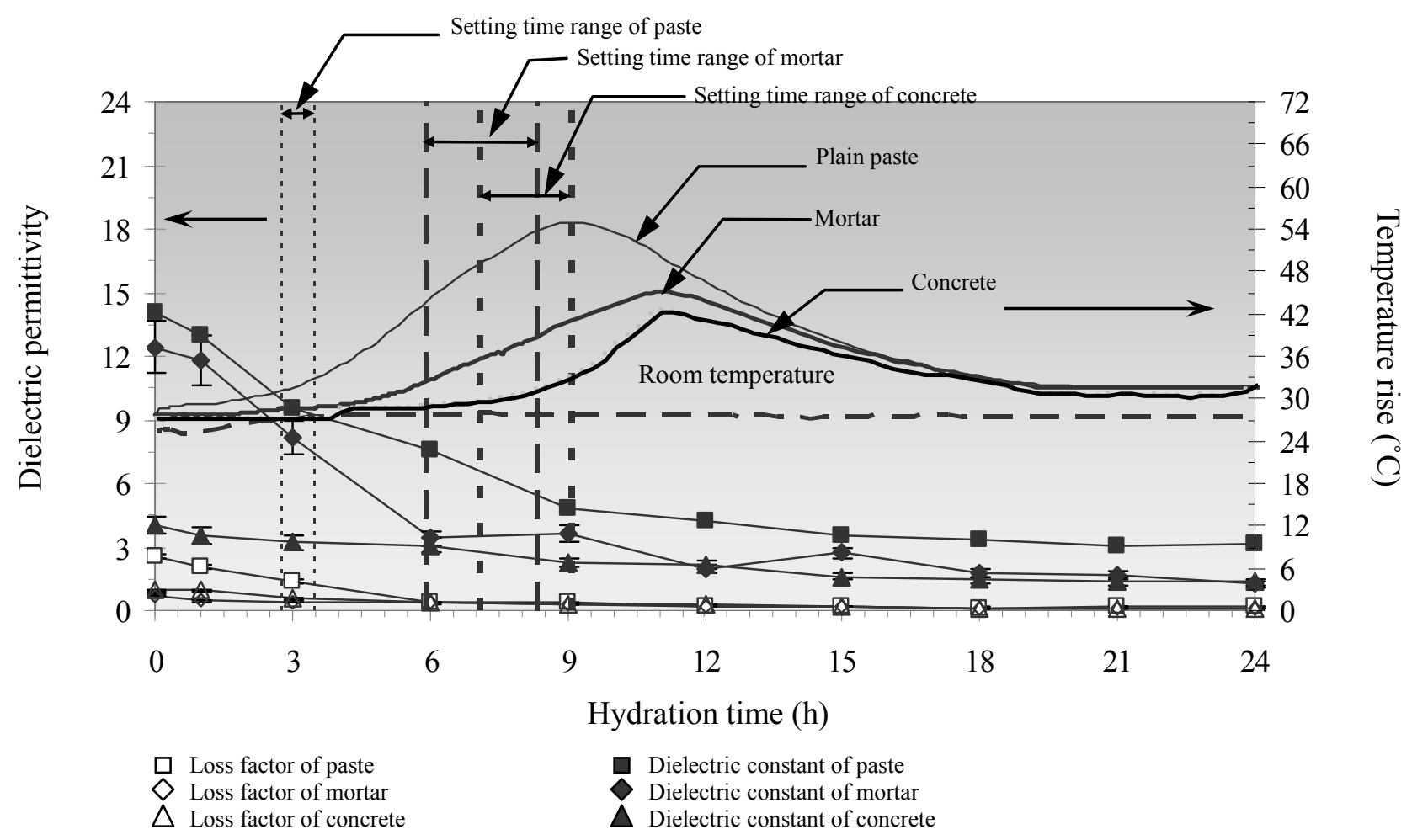

Figure 4. Dielectric permittivity of paste, mortar and concrete.

constant of the paste. Contrary to the SF paste, the com positions with PFA can dissolve it at a high rate, its fine- ness induces the bounding of its water molecules and ion-richness at the surface. As a result, the dielectric 
constant is lower than that of the plain cement paste. For loss factor evolution, the difference of loss factor is low between the conventional paste and SF-paste and large with PFA-paste; indicating that the remaining water content both during introduction and acceleratory periods in the paste has strong effect on the dielectric loss. On the other hand, the PFA particles can retain the free water in the paste system and this may raise the loss factor of the PFA-paste very high.

\subsection{Effect of Aggregates}

Figure 4 shows that the relative permittivity curves for the mortar and concrete are also similar to that of the conventional pastes but lower than the pastes. The decrease of cement content and the absorption of water molecules by aggregate surfaces induce a lower ions concentration in the system [9]. However, eventually, these parameters approach to constant. It can be compared in the setting time range that the slope of decrease rate of relative permittivity of the paste is somewhat higher than those of mortars and concretes. This is due to ion constraint by hydrated products which are high when compared with the aggregate-mixed ones.

\section{Conclusion}

Dielectric permittivity of cement-based materials is affected by initial water-to-cement ratio, cement types, pozzolan and aggregate types. However, although the volumetric fraction of water and superplasticizer in a given mixture is small, it strongly affects the dielectric permittivity of the cement due to its high dielectric permittivity. The change in the dielectric permittivity is relatively high and remains constant during the dormant period. After that it decreases rapidly when the hydration reaction resumes, and it continues to decrease during the acceleratory period.

\section{Acknowledgements}

The authors gratefully acknowledge the Thailand Research Fund (TRF) for supporting this research.

\section{REFERENCES}

[1] A. C. Metaxas, "Microwave Heating," Power Engineering Journal, Vol. 5, No. 5, 1992, pp. 237- 247. http://dx.doi.org/10.1049/pe:19910047

[2] K. Y. C. Leung and T. Pheeraphan, "Microwave Curing of Portland Cement Concrete: Experimental Results and Feasibility for Practical Applications," Construction and Building Materials, Vol. 9, No. 2, 1995, pp. 67-73. http://dx.doi.org/10.1016/0950-0618(94)00001-I

[3] R. G. Hutchinson, et al., "Thermal Acceleration of Portland Cement Mortars with Microwave Energy," Cement and Concrete Research, Vol. 21, No. 5, 1991, pp. 795799. http://dx.doi.org/10.1016/0008-8846(91)90174-G

[4] American Society for Testing and Materials, "Annual Book of ASTM Standard,” Vol. 4.01, Philadelphia, 2008.

[5] Hewlett Packard Corporation, "Dielectric Probe Kit 85070 A," Research and Development Unit, Test and Measurements Laboratories, Palo Alto, 1992.

[6] P. C. Hewlett, "Lea's Chemistry of Cement and Cementitious Material," 4th Edition, John Wiley \& Sons Inc., New York, 1998.

[7] F. H. Wittmann and F. Schlude, "Microwave Absorption of Hardened Cement Paste," Cement and Concrete Research, Vol. 5, No. 1, 1975, pp. 63-71.

http://dx.doi.org/10.1016/0008-8846(75)90108-8

[8] S. Wen and D. D. L. Chung, "Effect of Admixtures on the Dielectric Constant of Cement Paste," Cement and Concrete Research, Vol. 31, No. 4, 2001, pp. 673-677. http://dx.doi.org/10.1016/S0008-8846(01)00475-6

[9] H. C. Rhim and O. Buyukozturk, "Electromagnetic Properties of Concrete at Microwave Frequency Range," ACI Materials Journal, Vol. 95, No. 3, 1998, pp. 262-271. 